\title{
ON THE NEW SOURCE OF CHLOROMYCETIN, STREPTOMYCES OMIYAENSIS
}

\author{
By Hamao UMEZAWA, Tadakatu TAZAKI, Yoshiro OKAMI, \\ and SETSUko FUKUYAMA
}

The National Institute of Health of Japan, Tokyo

Chloromycetin was first isolated by Smith, Gottlieb, Ehrlich, Bartz and others (1 3) and by Umezawa and others (4) separately. The chloromycetin-producing strains isolated by American authors were determined to be a new species as Streptomyces venezuelae (5). Okami (6) of our laboratory designated our strain as Streptomyces pheochromogenus var. chloromyceiticus. They seem"to be identical each other. Later we isolated fourteen other chrolomycetin-producing strains which belong to the same species as the previous strains (7). So the chloromycetin production is one of the specific character of $S$. venezuelae or $S$. pheochromogenus var. chloromyceticus.

A strain which was presented in this paper was found to produce chloromycetin, . although it is different from S. venezuelae or S. pheochromogenus var. chloromyceticus. The isolation and characters are described in this paper.

I. The isolation of the strain No. 102

The isolation of this strain was partly described in our previous paper. The strain was isolated from the soil collected in Omiya city near Tokyo, when it was streaked on the nutrient agar containing chloromycetin at $0.025 \mathrm{mg}$ 'cc. When the broth culture of $E$. coli was sprayed on the colony of this strain growing on the nutrient agar and incubated, its growth was inhibited in the zone, up to $33.5 \mathrm{~mm}$ from the colony. The strain No. 102 grew well on the nutrient agar added with chloromycetin at $0.1 \mathrm{mg}$ cc. As described in the previous paper, the chloromycetinproducing strain inhibits $E$. coli and is more resistant to chloromycetin than the, other antibiotic streptomyces. In these characters the strain No. 102 resembled to' the chloromycetin-producing strain.

II. The identity of the antibiotic substance produced by the strain No. 102 with chloromycetin

The strain No. 102 produced the antibiotic substance in the nutrient broth with glycerol or starch, as shown in Table 1. The antibictic substance extracted with ethyl acetate and the ethyl acetate solution was concentrated to about one tenth volume by va.cuum distillation at $50^{\circ} \mathrm{C}$. The concentrated solution was dehydrated with anhydrous sodium sulfate and passed through alumina column. The fraction of the passed solution which contains the antibiotic substance was distilled to syrup in vacuum and the syrup was added with ethylene dichloride. After keeping a. $5^{\circ} \mathrm{C}$ for 
Table 1. Production of the antibiotic substance by the strain No. 102 by shaking culture.

\begin{tabular}{|c|c|c|c|c|c|c|}
\hline \multirow{3}{*}{ Carbon sources } & \multicolumn{6}{|c|}{ Potency and $\mathrm{pH}$} \\
\hline & \multicolumn{2}{|c|}{2 days } & \multicolumn{2}{|c|}{3 days } & \multicolumn{2}{|c|}{4 days } \\
\hline & $\mathrm{pH}$ & $\mu \mathrm{g} / \mathrm{cc}$ & $\mathrm{pH}$ & $\mu \mathrm{g} / \mathrm{cc}$ & $\mathrm{pH}$ & $\mu \mathrm{g} / \mathrm{cc}$ \\
\hline Glycerol ............ & 5.8 & 15 & 6.3 & 45 & 8.4 & 50 \\
\hline Glucose ................. & 5.5 & 0 & 4.7 & 0 & 4.6 & 0 \\
\hline Lactose $\ldots \ldots \ldots \ldots \ldots$ & 7.6 & 15 & 8.6 & 0 & 8.6 & 0 \\
\hline Dextrin ................. & 5.7 & 15 & 6.2 & 0 & 8.6 & 40 \\
\hline Starch & 5.4 & 0 & 5.5 & 60 & 8.4 & 90 \\
\hline
\end{tabular}

Base medium: Beef extract $0.5 \%$, peptone $0.5 \%, \mathrm{NaCl} 1 \%, \mathrm{pH} 7.0$.

Temperature of shaking culture: $25 \sim 28^{\circ} \mathrm{C}$.

Table 2. The extraction of the antibiotic substance produced by the strain No. 102 .

\begin{tabular}{|c|c|c|c|}
\hline . & $\underset{\mathrm{cc}}{\text { Volume }}$ & $\begin{array}{c}\text { Potency } \\
\mu \mathrm{g} / \mathrm{cc}\end{array}$ & Total pocency \\
\hline The broth & 1770 & 39 & 69000 \\
\hline 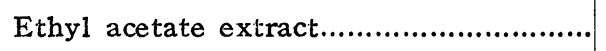 & 1000 & 61 & 61000 \\
\hline The concentrated ethyl acetate extract... & 400 & 1500 & 60000 \\
\hline \multicolumn{4}{|c|}{ Alumina column } \\
\hline 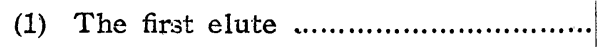 & 40 & 150 & 6000 \\
\hline (2) The second elute .................................. & 20 & 820 & 16400 \\
\hline (3) The third elute & 20 & 1440 & 28800 \\
\hline (4) The fourih elute ................................... & 20 & 0 & - \\
\hline 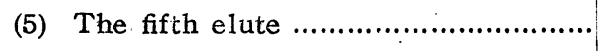 & 20 & 0 & - \\
\hline * The crystalline antibiotic ............ & - & - & $35 \mathrm{mg}$ \\
\hline
\end{tabular}

* Th second elute and the third elute were combined and concentrated to syrup by vacuum distillation. The latter was added with ethylene dichloride and kept at $-5^{\circ} \mathrm{C}$, and then the antibiotic c.ystals appeared.

Table 3. The identity of the antibiotic produced by the strain No. 102 and chloromycetin.

\begin{tabular}{|c|c|c|}
\hline . & Chloromycetin & The antibiotic of No. 102 \\
\hline 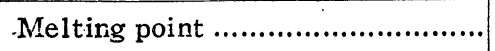 & \multirow[t]{2}{*}{$149.5 \sim 150.5^{\circ} \mathrm{C}$} & \multirow[t]{2}{*}{$148 \sim 149^{\circ} \mathrm{C}$} \\
\hline $\begin{array}{l}\text { Melting point of mixture of chlo- } \\
\text { romycetin and the antibiotic } \\
\text { from the strain of No. } 102 \ldots \ldots . . .\end{array}$ & & \\
\hline Percentage of carbon content....... & \multirow{3}{*}{$\begin{array}{r}41.63 \% \\
3.87 \% \\
9.48 \%\end{array}$} & \multirow{3}{*}{$\begin{array}{r}41.84 \% \\
3.86 \% \\
9.80 \%\end{array}$} \\
\hline Percentage of hydrogen content... & & \\
\hline Percentage of nitrogen content ... & & \\
\hline Diameter of inhibition zone & \multirow{3}{*}{$\begin{array}{l}18.95 \mathrm{~mm} \\
17.5 \mathrm{~mm}\end{array}$} & \multirow{3}{*}{$\begin{array}{l}19.0 \mathrm{~mm} \\
17.25 \mathrm{~mm}\end{array}$} \\
\hline $50 \mu \mathrm{g} / \mathrm{cc} \ldots \ldots \ldots \ldots \ldots \ldots \ldots . . . . . . . . . . . .$. & & \\
\hline $25 \mu \mathrm{g} / \mathrm{cc} \ldots \ldots \ldots \ldots \ldots \ldots \ldots \ldots . . . . . . . . .$. & & \\
\hline
\end{tabular}


24 hours, the needle crystals appeared. It is recrystallized with water and the antibiotic white thready crystals were obtained. It melted at $149 \sim 150^{\circ} \mathrm{C}$, and its composition was same as that of chloromycetin.

As shown in Table 3, the antibiotic isolated from the strain No. 102 is identical with chloromycetin in the melting point, the composition, and the antibiotic effect:

Characters of the strain No. 102

1) Morphology: Aerial mycelium with very scant branching, its width is $0.8-$ $1.2 \mu$, no spiral ; Conidia $1.0 \sim 1.2 \mu$ width and $2 \sim 3 \mu$ length.

2) Gelatin: White surface growth and plumose submerged growth; no aerial mycelium; no soluble pigment; slight liquefaction in crateriform.

3) Loeffler's serum medium: White moistened colony; no aerial mycelium; no soluble pigment; no liquefaction.

4) Nutrient agar: White to cream-colored, wrinkled colony ; no soluble pigment; no aerial mycelium.

5) Synthetic agar: Transparent to dark cream-colored, thin growth; no or scant white aerial mycelium; no soluble pigment.

6) Starch agar: Colorless thin colonies, almost all of which submerged; no aerial mycelium; no soluble pigment; starch is hydrolyzed (enzymatic zone is $6 \sim 7 \mathrm{~mm}$ in 7 day).

7) Glucose bouillon agar: White to cream-colored, bacteria-like colony ; ng aerial mycelium; no soluble pigment.

8) Blood agar: White to brownish white, moistened, restricted colony; no aerial mycelium; no soluble pigment; no hemolysis.

9) Egg medium: Brownish-yellow, wrinkled colony of which center is brown; no aerial mycelium; no soluble pigment.

10) Potato plug: White to cream-colored, network growth; no aerial mycelium; no soluble pigment; substrate unchanged.

11) Carrot plug: White to cream-colored, network growth; no aerial mycelium; no solublè pigment; substrate unchanged.

12) Milk: White surface growth ; no aerial mycelium ; no soluble pigment ; clearing after five days' incubation; acid is formed.

13) Tyrosinase: Negative.

IV. The differentiation of the strain No. 102 from the known species

S. venezuelae and S. pheochromogenus var. chloromyceticus, which were found to be the source of chloromycetin, produce a deep brown pigment in media containing protein substance. In their morphological examination slightly curved chains of conidia are observed, and their colonies on the synthetic agar are gray to light tan. However, the strain No. 102 does not produce a soluble pigment or such a 
curved chain of conidia, and its colony is transparent to dark cream colored. The strain No. 102 is clearly different from S. venezuelae or S. pheochromogenus var. chloromyceticus. The strain No. 102 seems to be included in the following groups indicated in the Bergey's Manual of Determinative Bacteriology 1949. (page 931 933) :

(1) Saprophytes; psychrophilic or mesophilic; no soluble pigment formed on gelatin or other media.

(2) Streptomyces isolated from animal tissues.

- Among the species indicated in these groups, S. cacaoi, S. hygroscopicus, S. flocculus, S. listeri and $S$. kimberi are somewhat resembling to the strain No. 102, though they are different from the latter in certain important characters.

$S$. cacaoi is strongly proteolytic and its aerial mycelium forms considerable spirals. Its growth on the nutrient agar is brown. In view of such characters it is different from the strain No. 102. S. hygroscopicus bears numerous spirals, its growth on glucose agar is chrome-yellow to brownish-orange and produce a soluble yellow pigment. Its aerial mycelium becomes moistened and exhibits dark, glisten ing patches. Such characters are not observed in the case of the strain No. 102.

S. flocculus is different from the strain No. 102 in its rose-colored growth in milk and liquefaction of coagulated serum.

$S$. listeri does not grow on egg medium, and dirty pink coloration is observed on patato plug. S. kimberi consists of mycelium of long straight profusely branching filaments forming circumscribed colonies on all media with abundant production of short straight and branched aerial mycelium. It does not hydrolyze starch. Therefore these two species are different from the strain No. 102. As above discribed, we can not find the species identical with the strain No. 102. Since the stroin No. 102 seems to belong to a new species, we would like tentatively to name this strain as Streptomyces omiyaensis.

\section{SUMMARY}

Strain (No. 102), which was isolated from the soil collected in Omiya city was found to produce chloromycetin. It is different from S. venezuelae or S. pheochromogenus var. chloromyceticus in the morphological and biological characters. It is also different from the species noted in the Bergey's Manual of Determinative Bacteriology. It was named as Streptomyces omiyaensis.

\section{REFERENCES}

1) Ehrlich, J., Bartz, Q. R., Smith, R. M. and Joslyn, D. A.: Chloromycetin, a new antibiotic from a soil actinomycete. Science, 106, 417, 1947.

2) Smith, R. M., Joslyn, D. A., Gruhzit, O. M., McLean, I. W., Penner, M. A. and Ehrlich, J.: Chloromycetin: Biological studies. J. Bact., 55, 425, 1948.

3) Bariz, Q. R. : Isolation and characterization of chloromycetin. J. Biol. Chem., 172, 445, 1948.

4) Umezawa, H., Tazaki, T., Kanari, H., Okami, Y. and Fukuyama, S.: Isolation of a crystalline 
antibiotic substance from a strain of streptmyces and its identity with chloromycetin. Jap. Med. J., 1, 358, 1948.

5) Ehrlich, J., Gottlieb, D., Burkholder, P. R., Anderson, L. E., and Pridham, T. G.: Streptomyces venezuelae, N. Sp., the source of Chloromycetin. J. Bact., 56, 467, 1948.

6) Okami, Y.: Studies on the characters of ancibiotic streptomyces, I: J. Antibiotics (Japan), 2, 593, 1948 ; J. Med. J., 1, 499, 1248.

7) Umezawa, H., Tazaki, T. and Fukuyama, S. : Resistances of antibiotic strains of screptomyces to chloromycetin and a rapid isolation method of 1 loromycetin producing strains. J. Antibiotics (Japan), 1249 (in press); Jap. Mad. J., 2, 73, 1949. 